\title{
STRUCTURAL EQUATION MODELING OF LATENT VARIABLES AFFECTING STOCK PRICES: EVIDENCE FROM NEPAL
}

\author{
Dipendra Karki *
}

\begin{abstract}
This study uses the structural equation model in Nepali stock market, chooses investor sentiment, monetary and macroeconomic factors as latent variables, and selects a few observed variables which can explain the latent variables to study the influence on stock prices. Based on existing empirical research conclusion, influence path diagram is designed and gets its path coefficient and causal path diagram using maximum likelihood estimation. The statistical significance of the results indicated that the causal relationships of Nepal's stock market as follows can be accepted; firstly, investor sentiment, macroeconomic indicators, and monetary factors have certain influence on stock prices, the investor sentiment has a positive correlation. Secondly, the investor sentiment has the major impact on stock prices; when investor sentiment is more stable and optimistic, stock prices will relatively be better. This research also provides certain reference to investors for rational investment decisions.
\end{abstract}

Key words: Structural, equation, stock, prices, investor, sentiment

\section{INTRODUCTION}

The pricing implication of common stocks has drawn considerable attention since the publication of seminal work of Markowitz (1952) - the mean-variance portfolio theory. Since then there is an ongoing debate on whether the market risk factors explain better or there are some other anomalies influencing common stock prices. There are many studies about the affecting factors on the stock prices. Some studies showed that there is in fact a relationship between stock prices and certain macroeconomic indicators, those studies were mostly conducted in developed economies.

The price volatility of the stock is the foundation of the stock market. Officer (1973) correlated the changes in stock prices to the volatility of macroeconomic variables. Fama and Schwert (1989), Fama (1981), and many others, documented a strong positive correlation between common stock returns and real economic variables like capital expenditures,

* Mr. Karki is Lecturer in Nepal Commerce Campus, Minbhavan, TU. 
industrial production, real GNP, money supply, lagged inflation and interest rates and found a negative relationship between stock prices and inflation in the US Market. But, what about less developed economies? Some studies showed no relationship between the economies and the financial markets of less developed countries like Asian markets. Fung and Lie (1990) explained that macroeconomic factors can't be reliable indicators for price movements in the Asian markets because of the inability of stock markets to fully capture information about the change in macroeconomic fundamentals. Establishing the empirical link between stock price volatility and macroeconomic variable has proven to be very challenging. Some studies find strong evidence that stock volatility increases during economic recessions (Bernanke, 1983). It seems that pricing volatility does not follow any pattern and not affected by economic variable. In some cases, it is closely related with macroeconomic variables and in some cases macroeconomic variables have no impact upon volatility. Researchers were successful in finding a relationship between stock prices and the different macroeconomic indicators in countries like Lithuania (Pilinkus, 2009), Turkey (Kandir, 2008), and Jordan (Maghayreh, 2003). Varying evidences of relationship between macroeconomic variables with stock prices were widely documented in the existing literature. Similarly, many others attempted to relate changes in stock prices and economic variables, including Fama (1981), and Alagidede and Panagiotidis (2010).

The studies on the effects of investor sentiment reveal that many general investors are puzzled about the stock prices in the market. The investor's main dilemma is whether or not to invest in the particular asset/assets, so that they can get bettersustainable and fair return of their investment with bearing minimum/zero risk. Mackay (1841) assembled a book of readings about Tulip-mania and some equally famous market "bubbles" which had a self-explanatory title: Extraordinary Popular Delusions and the Madness of Crowds. In contrast to Mackey's astonishing stories, Bachelier (1900) set a forth formal model in which security prices were random outcomes that had probabilities attached to them. Baker and Wurgler (2006) analyzed the impact of investor's sentiment on stock price mechanism in theory. He used the measure indexes of investor sentiment by selecting six principal components including; turnover rate, closed-end fund discount rate, IPO quantity, the yield of the first day, bonuses premium rate, and equity distribution ratio and built composite investor sentiment indexes to measure the mood. The study found the statistical significance 
of the construct variable mood and its strong influence on individual stocks. Zhang and Wang (2013) applied EGARCH model for the empirical analysis on their study and found that investor sentiment index could explain better on stock returns.

The importance of stock market as financial channels for saving and investment is gaining significant role in Nepalese economy. In general, volatility in the Nepal Stock Market is less than the average volatility of other developing countries (K.C, 2009). The reason is mainly low volume of trading equities due to low demand. However, in recent years pricing volatility has increased due to the increase in the volume of trading triggered by the speculative motives of investors. As evidenced from macroeconomic indicators of Nepal as of mid-July 2016, the ratio of stock market capitalization to GDP is about 94 percent. Economic stability and gaining investor's confidence, therefore, have become important conditions for financial development and economic growth of the country. In the light of these facts, it is important to examine how far the economic and noneconomic factors influence the stock market performance in Nepal.

\section{STATEMENT OF THE PROBLEM}

The relationship between the stock market and its determining factors is important to study for many reasons. First, it helps policy makers understand the full effect of prevailing and upcoming policies and regulations. Second, if investors were aware of this relationship and fully understood it, then they will make more informed investment decisions thus reducing their exposure to risk. And third, knowing which factor leads the other can help in reducing the shock factor because the public will be somewhat aware of what might happen in the economy or the financial market and thus will be able to take protective measures. Further, the relevance of the studies conducted in developed and big capital markets is yet to be seen in the context of smaller, developing and under-developed capital markets. Nepal has guided towards a change in the financial architecture of the economy since the adoption of economic liberalization policy in the beginning of 1980s. In the contemporary scenario, the activities in the financial markets and their relationships with the real sector have assumed significant importance. Thus, to sum up, the study basically deals with following research issues:

- What is the direction and magnitude of causal relationship between stock market and latent variables affecting stock prices in Nepal? 


\section{OBJECTIVE}

The major objective of this study is to analyze the influence of latent variables namely; Investor Sentiment, Monetary Factors and Macroeconomic Indexes on stock market performance in Nepal. The specific objectives are as follows.

- To examine the explanatory power of observed variables; Market Capitalization and Trading Volume on latent variable Investor Sentiment that influences stock prices.

- To analyze the influence of observed variables; Narrow Money Supply and Broad Money Supply on latent variable Monetary Factors that affects on stock market performance.

- To evaluate the descriptive power of observed variables; GDP, Inflation and Interest rate on latent variable Macroeconomic Indexes that have an effect on stock prices.

\section{REVIEW OF LITERATURE}

As regards ongoing debate on what works on stock pricing, the modern study on the behavior of stock market prices can be traced back to 1930, when Fisher explained how the market rate of interest and inflation affected the stock prices. Fisher (1930) found that stock prices are positively related to inflation, and hence stock investment can be used as a hedge against inflation. Several extensions have been made on this model incorporating several macro-economic and other structural variables in determining the stock market prices and performance. Jaffe and Mandelkar (1976), Nelson (1976), and Fama and Schwert (1977), among others, have argued that stock returns are inversely related to inflation. Similarly, Fama (1981) documented the negative relationship between stock returns and inflation. The evidences have suggested three dominant hypotheses, namely, tax effect, proxy effect, and the reverse causality hypotheses, explaining the negative effects of inflation on stock returns. This argument shows a contrary opinion to the priori expectation of Fisher hypothesis which assumes that stock returns are positively related to inflation and hence stock investment can be used as a hedge against inflation.

The proxy effect of Fama (1981) explained that real activity is positively related to common stock returns, but negatively related to inflation through the money demand effect. As a result, a negative relation between stock returns and inflation is possible to observe. In an attempt to establish 
a dynamic linkage between stock prices and macroeconomic variables, Ibrahim and Aziz (2003) reported a positive relationship between stock prices and inflation in the context of Malaysia. The study demonstrated that the observed positive relation between stock prices and inflation could provide better hedge against inflation for investors from stock investment in Malaysia. In relation to interest rate effect, several studies argue in favor of inverse relationship between stock returns and level of interest rates. Gan, Lee, Yong and Zhang (2006) observed that interest rate in the economy could determine stock returns consistently. Similarly, Kandir (2008) demonstrated a negative relationship between stock returns and interest rate. Such a negative relation implies that investors tend to invest less in stocks when interest rates go up causing stock price to fall. Despite of these evidences associated with interest rate effects, the studies also reveal that interest rate changes may not be enough to influence stock-price misalignments. For example, Bernanke and Gertler (2001) argued that the volatile nature of stock prices makes them hard to predict and that monetary authorities should only change interest rates in reaction to stock price movements, when they expect such movements to affect inflation. Goodfriend (1986) also noted no stable correlation between stock returns and short-term interest rates; as a result it would be difficult for interest rates to target stock price changes appropriately. Because of these controversies, this study attempts to identify the interest rate effect on Nepalese stock market. The empirical evidences in relation to real sectors' influence proxied by GDP on the stock returns also documented mixed results. It is argued that stock prices respond to the volatility in GDP. In this context, Gjerde and Saettem (1999) observed a significant positive association between the GDP, industrial production and stock prices. Contrary to these findings, Flannery and Protopapadakis (2002) reported no relation between stock returns and real GDP.

The studies on stock pricing behaviour of small and emerging capital markets lacked unanimous conclusion. Schwert (1989) documented weak evidence that macroeconomic volatility could help predict stock and bond returns volatility. Chaudhary (1996) found that the volatility in different smalls markets are explained by different variables. The recent studies have found evidences of both trend-following and contrarian behavior among various investor groups. Securities are bought by trend followers upon price appreciation and sell them upon depreciation, while contrarians trade in the opposite way. Such trading behavior has been found in both domestic and international markets. Moreover, prices in these markets have been found 
to be much more that the stocks' fundamental values. However, few others including Chan.

Though there are number of studies associated with stock pricing and stock market performance in developed capital markets, only few empirical works are found in the context of Nepal. In Nepalese context, researches are being conducted to understand the current working of the economic and the financial system. GC. and Neupane (2006) found the empirical evidence of long-run integration and causality of macroeconomic variables and stock market indicators in Nepal. In econometric sense, it depicts that the stock market plays significant role in determining economic growth and vice versa. The paper highlighted the importance of stock market development for fostering economic development. Baskota (2007) found that there is no persistence of volatility in Nepalese stock market and the stock price movements are not explained by the macroeconomic variables. Bhattarai and Joshi (2009) documented both short-run and long-run interdependence among stock index and some macroeconomic variables. History indicates that useful theoretical developments have not been uniform across all areas of stock pricing models in Nepal. Shrestha and Subedi (2014) revealed that the performance of stock market is found to respond positively to inflation and broad money growth, and negatively to interest rate. This suggests that, in Nepal, share investors seem to take equity as a hedge against inflation and consider stock as an alternative financial instrument. Further, availability of liquidity and the low interest rates stimulate the performance of the Nepalese stock market.

Many of the studies on the impact of some leading macroeconomic variables on stock prices concluded that one or other macroeconomic variables can predict stock market returns although the results vary among the studies. Moreover, no studies are found regarding the use of structural equation modeling to corporate the latent variables that affect stock prices. Thus, this study serves as an attempt to use structural equation model to identify the affecting factors of stock market performance in Nepal with a different set of variables and data of more recent period.

The economists Wright first put forward the concept of "path analysis" in 1921. Karl Joreskog, the Swedish statistician and psychologist, put forward the Structural Equation Model (SEM for short) in 1973 (Hendry, 1986). Since then, path analysis was gradually shifted to LISREL, AMOS and SEM software, which is called the path analysis oriented in the SEM. 
Structural equation modeling (SEM) is a statistical methodology that takes a confirmatory (i.e., hypothesis-testing) approach for simultaneous estimation of a structural theory bearing on some phenomenon. Typically, this theory represents causal processes that generate observations on multiple variables (Bentler, 1988). It's aim is mostly to confirm a research study design and is expressed by the casual model or path graph. In this model, the estimators are biased and inconsistent and estimated coefficients become meaningless if feedback is not considered. Formulation of SEM requires specification of equations in the model based on theory and it doesn't guarantee rightly estimated coefficients.

The analysis on the SEM begins with model identification first. The model is said to be identified if it meets the conditions for identification: Order and Rank conditions. For, order condition, if $g=$ no. of endogenous variables in system \& $\mathrm{m}=$ no. of variables (endogenous $\&$ exogenous) missing from equation under review then, $m=g-1$ (exactly identified); $\mathrm{m}>\mathrm{g}-1$ (over identified); $\mathrm{m}<\mathrm{g}-1$ (not identified). For rank condition, If rank of the coefficient matrix of all variables excluded from a particular equation (excluding coefficients of concerned equation) is g-1, then identified. Order condition is necessary but not sufficient, whereas rank is sufficient. If model is identified or over identified then model is identified. Simultaneous estimation method i.e. maximum likelihood estimation is used for the analysis of this recursive structural regression (SR) model. The impact levels of affecting factors, as well as correlations among latent factors and stock prices are presented and analyzed by using structural equation modeling.

\section{METHODOLOGY}

The review of early research papers reveal that there are several factors in determining stock prices. Based on the literature, this study constructs three latent variables namely; investor sentiment, monetary factors and macroeconomic indexes that affect stock prices. The important observed variables which can measure the latent variables, as suggested by the literature, are included in the model to make the structural equation model. Hence the conceptual framework of the variables (Figure 1.) 
Fig. 1: Conceptual Framework for Factors Affecting Stock Prices

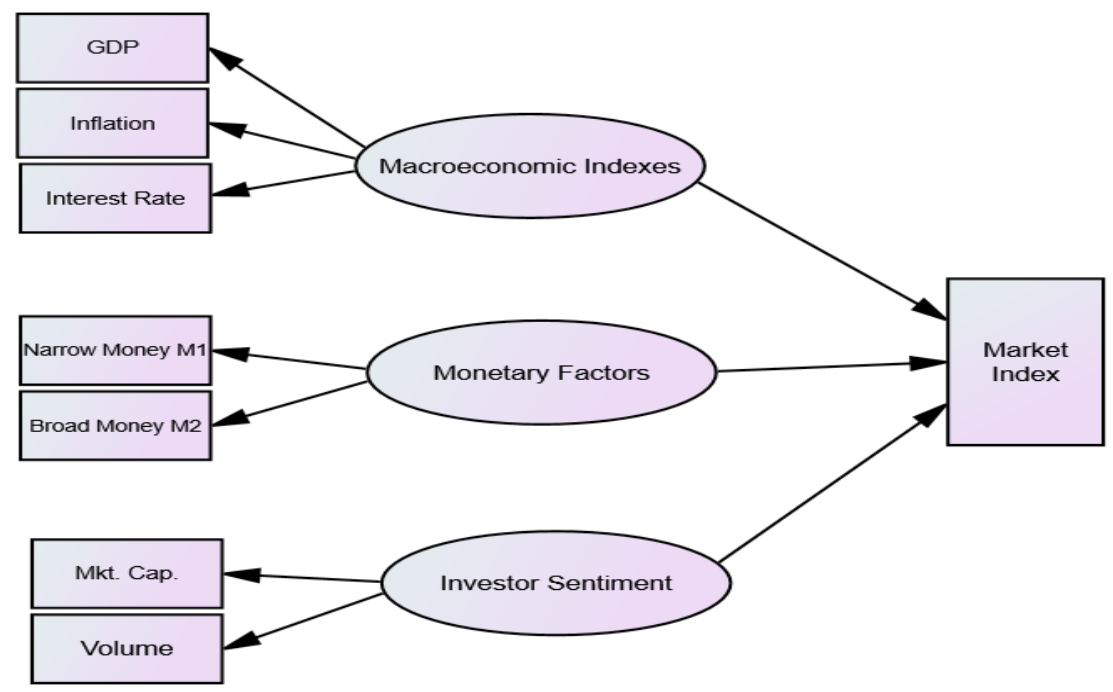

The explained variable is the Nepse/Market index (MI) which is the proxy of stock prices. The study uses structural equation model to analyze the affecting factors on stock prices. This study on Nepali stock market from the perspective of macroeconomic and investors' sentiment has very important theoretical and practical significance. From theoretical perspective it has importance on deepening our understanding of the field and from practical perspective it can improve the performance of our investment with the rational allocation of resources.

\section{DESCRIPTION OF VARIABLES}

The influence of selected factors on stock prices is analyzed using structural equation model where stock prices represented by market index (MI) is the endogenous variable, and investor sentiment, monetary factors and macroeconomic indexes are the exogenous variables. NEPSE/Market Index (MI) is a market value weighted index composed of the shares of listed companies from different sectors in the Nepalese stock exchange. It gives the investor a general idea about the direction and performance of the market. While measuring the impact of macroeconomic and other affecting variables on stock prices, Market Index was used as the proxy of stock prices in several prior studies like; Mukherjee and Naka (1995), Osamwoyi and Osagie (2012), among others.

The selected observed variables that can explain the latent variables are; Market capitalization (MC), Volume (V), Narrow money supply (M1), 
Broad money supply (M2), Gross domestic product (GDP), Inflation (INF) and Interest rate (IR). Market capitalization (MC) reflects the changes of total price of the listed securities in a time, if MC rises stable then investor sentiment is optimistic. Volume (V) is the sum amount of transactions happens in a particular period. It represents the market liquidity, it reflects the investor's participation, if investor sentiment is optimistic, volume will be large.

GDP is used as a proxy of real aggregate economic activity in an economy. In this study nominal GDP has been considered for analysis. Higher GDP represents economic prosperity of the country and stock returns are expected to influence positively. Inflation (INF) has puzzle relationship with stock returns. As the worth of rupees gets reduced due to high inflation, it is expected that the stock prices would be high in the time of Inflation ( Ibrahim \& Aziz, 2003). But, higher inflation reflects higher discount rate leading to the lower value of equities. The interest rate (IR) is another important economic factor affecting the value of common stocks. The reduction in interest rates reduces the cost of borrowing and thus serves as an incentive for expansion. This will have a positive effect on future expected returns for the firm, so as stock prices. The IR used in this study is the weighted average 91 days T-bills rate, annualized percent as of yearend. Narrow money supply (M1) consists of currency held by public (C) and demand deposits (DD) held at the banking sectors. Symbolically, $\mathrm{M} 1=\mathrm{C}+\mathrm{DD}$. Broad money supply (M2) consists of narrow money supply and time deposit (TD) held at commercial banks. Symbolically, M2=M1+TD. Both the monetary factors reflect the liquidity status in the market and hence, expected to have positive relationship with stock prices as well as investor sentiment. To smoothen the data natural logarithms has been taken for the variables; MC, V, GDP, M1, and M2. The specific variable design is as given (Table 1).

Table 1: Description of Variables

\begin{tabular}{|l|l|}
\hline Variables & Observed Variables \\
\hline Latent Variables & \\
\hline Investor Sentiment (Inv.Senti.) & Market Capitalization (MC), Volume (V) \\
\hline Monetary Factors (MF) & $\begin{array}{l}\text { Narrow Money Supply (M1), Broad } \\
\text { Money Supply (M2) }\end{array}$ \\
\hline Macroeconomic Indicators (MEI) & GDP, Inflation (INF), Interest Rate (IR) \\
\hline Endogenous variables & \\
\hline Stock Market Prices & Market Index (MI) \\
\hline
\end{tabular}




\section{MODEL}

The theoretical statement could be framed as:

$$
M I_{i t}=\alpha 0+\beta_{i} X_{i t}+\varepsilon i . t
$$

Where,

$M I_{i t}=$ Stock market index

$\alpha 0=$ Constant term, assumed to be constant over time

$\beta_{i}=$ Coefficient of independent variables

$X_{i t}=$ Vector of latent variables (macroeconomic, monetary factor, and investor sentiment) for latent variable $\mathrm{i}$ at time $\mathrm{t}$.

$\varepsilon i t=$ Stochastic error term assumed to have zero mean, constant variance and normal distribution.

Upon completion of indicator design based on the theory and former research conclusion, this study uses AMOS17.0 software to construct the initial structural equation that shows a path model as given ( Figure 2).

Figure 2: Preliminary Design of SEM Path Diagram

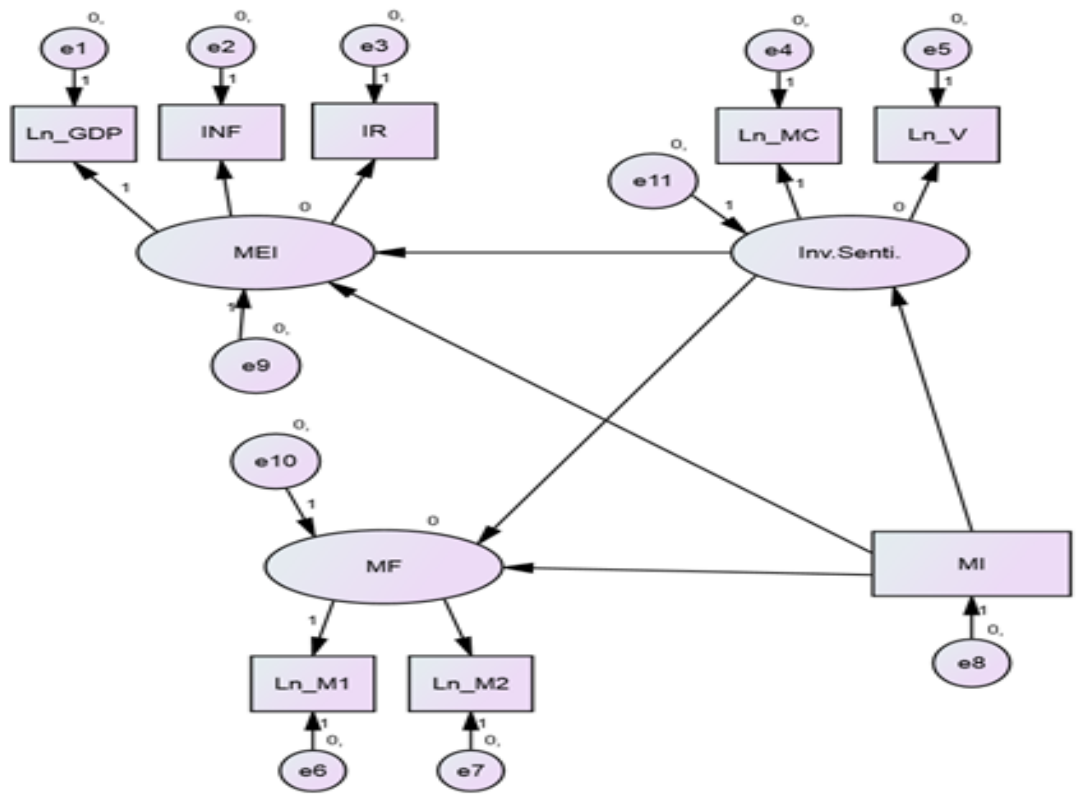

Note: $\mathrm{e}_{\mathrm{i}}$ are residuals of all observed and unobserved variables. 


\section{MODEL SPECIFICATION}

\section{Parameter estimation and analysis}

This study uses macroeconomic, monetary and stock data for the period of 1994 to 2016 covering 23 years to study the influence factors of stock prices. The secondary data were retrieved from various sources like; Government of Nepal-Ministry of finance (MoF), Nepal Rastra Bank (NRB) and Nepal Stock Exchange Ltd. (NEPSE), then uses Amos17.0 software to carry on the fitting test.

Latent variables are scaled and errors, like latent variables, are also scaled for identification. For this, we assign loading for direct effect on any one of its indicators to 1 that is known as reference variable as GDP for factor MEI. Disturbances (e) in structural regression (SR) are assigned a scale equal to 1 . Total no of parameters that can be estimated is limited by number of observations. With ' $\mathrm{P}$ ' observed variables, no. of observations equal $\mathrm{P}(\mathrm{P}+1) / 2$, for our model that has 7 observed variables, have 28 $[7(7+1) / 2]$ no. of observations. $\mathrm{D}_{\mathrm{fm}}=\mathrm{p}-\mathrm{q}$ is termed as the model's degree of freedom. Our model contains 56 parameters, 28 free parameters, 44 sample moments leading to $16 \mathrm{Dfm}$. When the model box is (OK: Default model), it means that it can display parameter estimates, and that there is no problem in theory model defining. With that standard, the model is fitted and the result is as given ( Figure 3).

Figure 3: Standardized Path Diagram and Path Coefficient (ML Estimation)

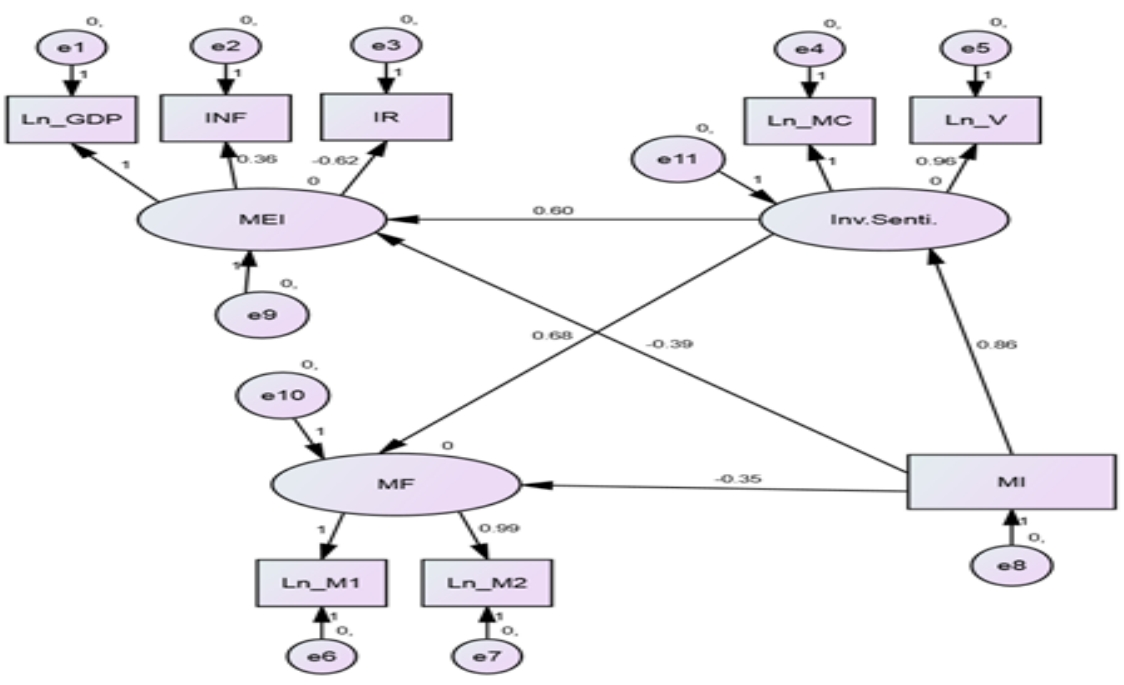




\section{MODEL FIT}

The aim here is to determine the degree to which sample variance data fit the SEM; commonly used criteria are: Chi-square $(\chi 2)$, the goodnessof-fit index (GFI), comparative fit index (CFI) and the root-mean-square residual (RMR). Asberg, Bowers, Renk and McKinney (2008) suggest that the model is satisfactory with comparative fit index (CFI) greater than or equal to 0.90 , the parsimonious fit index (PFI) greater than or equal to 0.60 , and the squared error of approximation (RMSEA) less than or equal to 0.10. Schreiber, James, Nora, Atage, Borlow \& King, (2006) indicate a full set of criteria for an accepted SEM (Table 2).

Table 2: Criteria for an accepted SEM

\begin{tabular}{|c|c|c|}
\hline Indexes & Shorthand & $\begin{array}{l}\text { General rule for acceptable } \\
\text { fit }\end{array}$ \\
\hline \multicolumn{3}{|l|}{ Absolute/predictive fit } \\
\hline Chi-Square & $\chi^{2}$ & Ratio of $\chi^{2}$ to $\mathrm{df} \leq 2$ or 3 \\
\hline Akaike information criterion & AIC & Smaller the better \\
\hline Browne-Cudeck criterion & $\mathrm{BCC}$ & Smaller the better \\
\hline Bayes information criterion & $\mathrm{BIC}$ & Smaller the better \\
\hline Consistent AIC & CAIC & Smaller the better \\
\hline Expected cross-validation index & ECVI & Smaller the better \\
\hline \multicolumn{3}{|l|}{ Comparative fit } \\
\hline Normed fit index & NFI & $\geq 0.95$ for acceptance \\
\hline Incremental fit index & IFI & $\geq 0.95$ for acceptance \\
\hline Tucker-Lewis index & TLI & $\geq 0.95$ for acceptance \\
\hline Comparative fit index & CFI & $\geq 0.95$ for acceptance \\
\hline Relative noncentrality fit index & RNI & $\geq 0.95$ similar to $\mathrm{CFI}$ \\
\hline \multicolumn{3}{|l|}{ Parsimonious fit } \\
\hline Parsimony-adjusted NFI & PNFI & Very sensitive to model size \\
\hline Parsimony-adjusted CFI & PCFI & Sensitive to model size \\
\hline Parsimony-adjusted GFI & PGFI & Closer to 1 the better \\
\hline \multicolumn{3}{|l|}{ Other } \\
\hline Goodness-of-fit index Adjusted GFI & GFI/AGFI & $\geq 0.95$ \\
\hline Root mean square residual & RMR & Smaller, the better \\
\hline Standardized residual & SRMR & $\leq 0.08$ \\
\hline Weighted root mean residual & WRMR & $<0.90$ \\
\hline $\begin{array}{l}\text { Root mean square error of } \\
\text { approximation }\end{array}$ & RMSEA & $<0.06$ to 0.08 or below $(0.1)$ \\
\hline
\end{tabular}


The criteria for an accepted SEM, presented in the Table 2, are used to assess the model fit for used data.

Table 3 illustrates the test statistics estimated for whole model to identify the fit measures.

Table 3: Model Fit Summary

\begin{tabular}{|c|c|c|c|c|c|}
\hline \multicolumn{6}{|l|}{ CMIN } \\
\hline Model & NPAR & CMIN & DF & $\mathbf{P}$ & $\begin{array}{l}\text { C M I N / } \\
\text { DF }\end{array}$ \\
\hline Default model & 28 & 27.157 & 16 & .040 & 1.697 \\
\hline Saturated model & 44 & .000 & 0 & & \\
\hline Independence model & 8 & 427.609 & 36 & .000 & 11.878 \\
\hline \multicolumn{6}{|l|}{ Baseline Comparisons } \\
\hline Model & NFI Delta1 & RFI rho1 & IFI Delta2 & TLI rho2 & CFI \\
\hline Default model & .936 & .857 & .973 & .936 & .972 \\
\hline Saturated model & 1.000 & & 1.000 & & 1.000 \\
\hline Independence model & .000 & .000 & .000 & .000 & .000 \\
\hline \multicolumn{6}{|l|}{ NCP } \\
\hline Model & NCP & LO 90 & HI 90 & & \\
\hline Default model & 11.157 & .527 & 29.628 & & \\
\hline Saturated model & .000 & .000 & .000 & & \\
\hline Independence model & 391.609 & 328.710 & 461.957 & & \\
\hline \multicolumn{6}{|l|}{ RMSEA } \\
\hline Model & RMSEA & LO 90 & HI 90 & PCLOSE & \\
\hline Default model & .174 & .038 & .284 & .058 & \\
\hline Independence model & .688 & .630 & .747 & .000 & \\
\hline \multicolumn{6}{|l|}{ AIC } \\
\hline Model & AIC & BCC & BIC & CAIC & \\
\hline Default model & 83.157 & 119.157 & & & \\
\hline Saturated model & 88.000 & 144.571 & & & \\
\hline Independence model & 443.609 & 453.894 & & & \\
\hline \multicolumn{6}{|l|}{ ECVI } \\
\hline Model & ECVI & LO 90 & HI 90 & MECVI & \\
\hline Default model & 3.616 & 3.153 & 4.419 & 5.181 & \\
\hline Saturated model & 3.826 & 3.826 & 3.826 & 6.286 & \\
\hline Independence model & 19.287 & 16.553 & 22.346 & 19.735 & \\
\hline
\end{tabular}


Among many fit measures, it is worth pointing out that the interpretation of many (but not all) fit measures depends on CMIN having a chi square $(\chi 2)$ distribution for correctly specified models. Many fit measures depend on the ratio CMIN/DF, which should be close to $1(\leq 2)$ for a correct model. In maximum likelihood estimation, calculating the likelihood ratio $\chi 2$ statistics requires fitting the saturated model. Whether or not Amos fits the saturated model is the evidence for the correct specification of the model.

The structural model fit is very good with chi square $(\chi 2)$ distribution; $\mathrm{CMIN} / \mathrm{df}=1.697$, and $\mathrm{p}$-value $=0.04$; IFI (Incremental Index of Fit $)=0.973$; CFI $($ Comparative Fit Index $)=0.972$; Noncentrality parameter (NCP) estimate is framed within the bounds of confidence interval as suggested by Steiger (1990). Our hypothesized model yielded a noncentrality parameter of 11.157 . This value represents the $\chi 2$ value minus its Dfm (27.157-16). The confidence interval indicates that we can be 90 percent confident that the population value of noncentrality parameter $(\lambda)$ lies between 0.527 to 29.628. However,

RMSEA (Root Mean Square Error of Approximation) $=0.174$ PCLOSE(0.058) indicate the model doesn't fit very well as the value below 0.10 is preferred. This may be due to the reason of small sample size and large number of estimated parameters in the model. When sample size is small the RMSEA tends to overreject true population model (Hu \& Bentler, 1999). Thus, the cutpoints for RMSEA should be interpreted with caution in this model. GFI is not reported as means are explicit model parameters. Because the published GFI/AGFI formulae ignore the residuals of the mean vector, using these GFI fit indices with means-level models is not logically appropriate.

Akaike's Information Criterion (AIC) and Bozdogan's consistent version of AIC (CAIC) both criterion address the issue of parsimony in the assessment of model fit. The Browne-Cudeck Criterion (Browne \& Cudeck, 1989) and the Bayes Information Creiterion (BIC) operate in the same manner as AIC and CAIC but they impose grater penalties than either AIC or CAIC for model complexity. Our results for all four of these fit indices pass the test and showed that the fit statistics for the hypothesized model are substantially smaller than they are for either the independence or the saturated models. 
The Expected Cross-Validation Index (ECVI) is estimated as a means of assessing the likelihood that the model cross-validates across similar-sized samples from the same population (Browne \& Cudeck, 1989). It assumes a comparison of models; the model having the smallest ECVI value exhibits the greatest potential for replication. In assessing our fit statistics, the lower ECVI value (3.616) for the hypothesized model, compared with both the independence and saturated models, represents the best fit to the data.

These indexes indicate a strong predictive validity of the model for the used data.

\section{MODEL TEST}

The study uses the recursive model. According to the model study, we estimated the path coefficients using the method of ML and got the path diagram Figure 3. In general, the parameter estimates should exhibit the correct sign and size, and be consistent with the underlying theory. Following table 4 gives the test result of parameter hypothesis:

Table 4: Standardized regression coefficients and the statistical test (ML Estimation)

\begin{tabular}{|l|l|l|c|c|c|c|c|}
\hline & & & & & & \\
& & & & & & \\
& & & & & & \\
& & & & & & \\
& & & & & & \\
\hline Inv.Sentiment & $<---$ & Market Index & .857 & .004 & .000 & 7.447 & $* * *$ \\
\hline Macroeconomy. & $<---$ & Market Index & -.390 & -.001 & .000 & -4.878 & $* * *$ \\
\hline Monetary Factor & $<---$ & Market Index & -.345 & .001 & .000 & -4.168 & $* * *$ \\
\hline Macroeconomy & $<---$ & Inv.Sentiment & 1.319 & .600 & .038 & 15.842 & $* * *$ \\
\hline Monetary Factor & $<---$ & Inv.Sentiment & 1.278 & .677 & .047 & 14.452 & $* * *$ \\
\hline Ln_GDP & $<---$ & Macroeconomy & .995 & 1.000 & & & \\
\hline INF & $<---$ & Macroeconomy & .361 & 1.408 & .767 & 1.836 & .066 \\
\hline IR & $<---$ & Macroeconomy & -.619 & -2.454 & .662 & -3.710 & $* * *$ \\
\hline Ln_MC & $<---$ & Inv.Sentiment & .986 & 1.000 & & & \\
\hline Ln_V & $<---$ & Inv.Sentiment & .956 & 1.124 & .084 & 13.358 & $* * *$ \\
\hline Ln_M1 & $<---$ & Monetary Factor & .996 & 1.000 & & & \\
\hline Ln_M2 & $<---$ & Monetary Factor & .999 & 1.233 & .025 & 49.525 & $* * *$ \\
\hline
\end{tabular}

Note: <--- means the influence path of variables. 
Among them, Estimate represents the estimated value of the influence coefficient, S.E. the standard error and C.R. is the Critical Ratio test statistic which represents the parameter estimate divided by its standard error, as such, it operates as a z-statistic in testing that the estimate is statistically different from zero. Based on the probability level of 0.5 , the test statistic needs to be $> \pm 1.96$ before the hypothesis can be rejected. Obviously, three latent variables; Investor sentiment, Macroeconomic indicator, Monetary factors, along with seven observed variables are all passed the test and reach the significance level. It also means that C.R. > 1.96. However, the estimate of INF to Macroeconomic indicator has passed the test at 10percent level of significance.

\section{RESULT AND DISCUSSION}

After analysis, the causal relationships as followed can be accepted:

- Investor sentiment, Macroeconomic indicator and Monetary factor have a certain influence on stock prices, and the biggest impact on stock prices is investor sentiment, it reaches 0.857 , and then followed by macroeconomic indicator and monetary factors.

- Investor sentiment has positive correlation with stock returns. It indicates that increase in investor confidence leads to the increase in stock prices. The result is consistent with the findings of Hua, Shiting, and Qiubai (2013). The relationships of macroeconomic indicators and the monetary factors to market index are negative. In the case of macroeconomic indicators, the literature review on observed variables Interest rate (IR) and Inflation (INF) documented the evidence of negative relationship with stock prices. The negative relation of interest rate implies that investors tend to invest less in stocks when interest rates go up causing stock price to fall (Kandir, 2008). The negative effects of inflation on stock prices is explained by three dominant hypotheses, namely, tax effect, proxy effect, and the reverse causality hypotheses, explaining the negative effects of inflation on stock returns (Fama, 1981). The justification for the negative relation of monetary factors on stock prices could be made as the increase in money supply M1 \& M2 rises the level of inflation which brings higher discount rates and hence the lower value of equities. The above causes are justifiable to have the negative effects of latent variables; macroeconomic indicators and 
monetary factors and positive effect of investor sentiment with stock prices.

- In the investor sentiment factors, the trading volume (V) has estimated coefficient 0.96 that shows a significant influence on stock prices, the higher is the volume, higher the stock prices.

- The impact of macroeconomic indicators on stock prices is only after investor sentiment, it reaches -0.39 . Assigning loadings 1 to GDP, the market interest has the better explaining capacity (-0.62) to stock prices. The higher the interest rate, lower is the stock prices. The monetary factor also has a certain influence on stock prices.

- There also have a certain relationship between the investor sentiment, Macro economy and Monetary factors. While looking in unstandardized estimate, the monetary factor has positive effects on investor sentiment; the influence coefficient is 0.68 . This shows that higher the money supply in the market, the higher will be the investor confident on rising stock prices. The macroeconomic indicators also have positive effects on investor sentiment; the influence coefficient is 0.60 , the better the macroeconomic indices, the investor sentiment will be more optimistic.

\section{CONCLUSION}

Stock investment activity has become a new hot spot of human financial activities, and an empirical analysis of the influence factors on stock prices can provide certain reference for investors and stakeholders. This paper uses the structural equation model, chooses stock prices as explained variable, and investor sentiment, macroeconomic indicators and monetary factors as latent variables, then selects observed variables which can explain latent variables to do empirical analysis, finally finds that investor sentiment has the biggest influence on stock prices followed by macroeconomic indicators and monetary factors. Knowing the positive relationship of investor sentiment and negative relations of macro-economy and monetary factors to the stock prices, investors can make scientific decisions and invest rationally. In addition, it provides some suggestions for improving the efficiency of investment from three angles that is the investors, listed companies and securities institutions to ensure the healthy and stable development of the Nepali capital market. 


\section{WORKS CITED}

Alagidede, P., \& Panagiotidis, T. (2010). Can common stocks provide a hedge against inflation? Evidence from African countries. Review of Financial Economics, (19), pp. 91-100.

Asberg, K. K., Bowers, C., Renk, K., \& McKinney, C. (2008). A structural equation modeling approach to the study of stress and psychological adjustment in emerging adults. Child Psychiatry Human Development, 39(4), pp. 481-501.

Bachelier, L. (1900). Theory la speculation. Gauthiers-Villars.

Baskota, N.P. (2007). Stock price volatility in Nepal. An unpublished M. Phil. thesis submitted to Faculty of Management. Kathmandu: TU.

Bernanke, B.S. (1983). Nonmonetary effects of the financial crises in the propagation of the great depression. American Economic Review, (73), pp. 257-76.

Bernanke, B. S., \& Gertler, M. (2001). Should central banks respond to movements in asset prices?. The American Economic Review, 91(2), pp. 253-257.

Bentler, P.M. (1988). Causal modeling via structural equation systems. Handbook of Multivariate Experimental Psychology $\left(2^{\text {nd }}\right.$ ed. pp.317-335). New York: Plenum.

Bhattarai, R.C., \& Joshi, N.K. (2009). Dynamic relationship among the stock market and macroeconomic factors: Evidence from Nepal. South Asia Economic Journal, 10(2), pp. 451-469.

Browne, M.W., \& Cudeck, R. (1989). Single sample cross-validation indices for covariance structures. Multivariate Behavioral Research, (24), pp. 445-455.

Chaudhary, T. (1996). Stock market volatility and the crash of 1987: Evidence from six emerging markets. Journal of International Money and Finance, (15), 969-981.

Fama, E.F. (1981). Stock returns, real activity, inflation, and money. The American Economic Review, 71(4), pp. 545-565.

Fama, E.F., \& Schwert, G.W. (1977). Asset returns and inflation. Journal of Financial Economics, 5(2), pp. 115-146.

Fisher, I. (1930). The theory of interest. New York: MacMillan. 
Flannery, M. J. \& Protopapadakis, A. A. (2002). Macroeconomic factors do influence aggregate stock returns. Review of Financial Studies, (15), pp. 751-782.

Fung, H. G., \& Lie, C. J. (1990). Stock market and economic activities: A causal analysis. Pacific-Basin Capital Markets Research.

Gan, C., Lee, M., Yong, H., \& Zhang, J. (2006). Macroeconomic variables and stock market interactions: Newzealand evidence. Investment Management and Financial Innovations, 3, pp. 89-101.

GC, S.B., \& Neupane, S. (2006). Stock market and economic development: A causality test. The Journal of Nepalese Business Studies, 3(1), pp. 36-44.

Gjerde, O. \& Saettem, F. (1999). Causal relations among stock returns and macroeconomic variables in a small, open economy. Journal of International Finance, (9), pp. 61-74.

Goodfriend, M. (1986). Monetary mystique: Secrecy and central banking. Journal of Monetary Economics, 17(1), 63-92.

Hendry, D.F. (1986). Econometric modeling with cointegrated variables: An overview. Oxford Bulletin of Economics and Statistics, 48, pp. 201-212.

Hua, L., Shiting, D., \& Qiubau, S. (2013). An empirical study on affecting factors of stock returns based on the structural equation modelmanufacturing as the example. Computer Modeling and New Technologies, 17(5C), pp. 219-222.

Hu, L.T., \& Bentler, P. M. (1999). Cutoff criteria for fit indexes in covariance structure analysis: Conventional criteria versus new alternatives. Structural Equation Modeling, (6), pp. 1-55.

Ibrahim, M.H., \& Aziz, H. (2003). Macroeconomic variables and the Malaysian equity market: A view through rolling sub samples. Journal of Economic Studies, 30(1), pp. 6-27.

Jaffe, F., \& Mandelker, G. (1976). The Fisher effect for risky assets: An empirical investigation. The Journal of Finance, 31(2), pp. $447-$ 458.

Kandir, S. (2008). Macroeconomic variables, firm characteristics and stock returns: Evidence from Turkey. International Research Journal of Finance and Economics, (16), pp. 35-44. 
44 STRUCTURAL EQUATION MODELING OF LATENT VARIABLES ...

KC, I. D. (2009). The cross section of stock market returns. Quantitative Analysis, (32), pp. 463-489.

Mackay, C. (1841). Extraordinary popular delusions and the madness of crowds. New York: Harmony Books.

Maghayreh, A. (2003). Causal relations among stock prices and macroeconomic variables in the small, open economy of Jordan. Journal of King Abdul Aziz University, 17(2), pp. 4-10.

Markowitz, H. (1952). Portfolio selection. Journal of Finance, (7), pp. $77-$ 91.

Mukherjee, T., \& Naka,A. (1995). Dynamic linkage between macroeconomic variables and the Japanese stock market: An application of a vector error correction model, Journal of Financial Research (18), pp. 223-37.

Nelson, C. (1976). Inflation and rates of return on common stocks. The Journal of Finance, 31(2), pp. 471-487.

Officer, R.R. (1973). The variability of the market factor of the New York Stock Exchange. Journal of Business, (46), pp. 434-453.

Osamwonyi, I.O., \& Osagie, E.I.E. (2012). The relationship between macroeconomic variables and stock market index in Nigeria. Journal of Economics and Management, 3(1), pp. 55-63.

Pilinkus, D. (2009). Stock markets and macroeconomic variables: Evidences from Lithuania. Journal of Economics and Management, (14), pp. 884-893.

Schreiber, J., James, B., Nora, A., Stage, F. K., Barlow, E., \& King, J. (2006). Reporting structural equation modeling and confirmatory factor analysis result: A review. The Journal of Educational Research, 99(6), pp. 323-337.

Schwert, G. W. (1989). Why does stock market volatility change over time? Journal of Finance, (44), pp. 1115-1145.

Shrestha, P.K., \& Subedi, B.R. (2014). Determinants of stock market performance in Nepal. NRB-Economic Review, 26(2), pp. 25-40.

Zhang, L., \& Wang, L. (2013). Research on investor sentiment and stock returns based on the a-share market data. Journal of Industrial and Technology Forum, 12(20), pp. 111-120. 